\title{
The Influence of Organizational Culture on E-Commerce Adoption
}

\author{
Hani Al-Dmour ${ }^{1}$, Maram Nweiran ${ }^{1} \&$ Rand Al-Dmour ${ }^{1}$ \\ ${ }^{1}$ The University of Jordan, Jordan \\ Correspondence: Hani Al-Dmour, The University of Jordan, Jordan. E-mail: dr_dmourh@yahoo.com
}

Received: January 27, 2017

Accepted: March 20, 2017

Online Published: August 12, 2017

doi:10.5539/ijbm.v12n9p204

URL: https://doi.org/10.5539/ijbm.v12n9p204

\begin{abstract}
This study aims to investigate the influence of different organizational cultures on e-commerce adoption in Jordanian commercial banks. The study is of value to banks by helping them to evaluate their readiness to adopt e-commerce through reviewing the type of leadership, risk appetite, innovation and e-commerce activities. As banks are designing and deploying a range of new e-commerce products, the importance of pursuing and conducting business online becomes relevant, as, if they fail to respond to the opportunities, banks could be consigned to a largely secondary role as e-commerce shifts over time. E-commerce is progressing by creating new streams of competition and compelling banks to make choices about services they offer, networks branch size and distribution, and the extent of their support for interbank payment network.

The major findings of this study have indicated that there is a positive correlation between organizational culture and e-commerce adoption. More specifically, the study has revealed that the adhocracy system of organization and management is more prevalently implemented in e-commerce activities than other systems in Jordanian commercial banks. In contrast, hierarchy cultural commercial banks are not adopters of e-commerce activities, and the organizational culture differences explain these issues. A number of recommendations have appeared in light of findings; managers need to place greater focus and attention on their organization culture if they pursue innovation/imitation of strategies. Jordanian commercial banks are advised to focus on activities that enhance e-commerce adoption as to evaluate its status quo in terms of characteristics and the prevailing culture type. This is in order to successfully apply the adoption effectively and efficiently by filling the gap between the association of organization culture and e-commerce adoption.
\end{abstract}

Keywords: e-commerce, adoption, organizational culture, commercial banks, Jordan

\section{Research Background}

The last few decades have witnessed a technological revolution stimulated by the extensive spread of the internet, web technologies and their functions. Electronic commerce is commonly used as part of the information technology revolution, and has become a point of focus in world trade. E-commerce can be one of the most important value-generating investments a business can pursue, and the key is the innovative decision to move from a traditional business to invest in technology (Epstein, 2004). With the growth and development of the internet, it didn't take long to consider the World Wide Web (WWW) as an opportunity for commercial entrepreneurs to start developing an online virtual existence (Chan, 1997). Rapidly, the online market was born, providing a virtual place of exchanging goods and services to satisfy supply and demand (Wigand, 1997). Goods are purchased and services are delivered to the customer's doorstep. This sensation was known as electronic commerce or e-commerce (Biederman, 2012). Most types of organizations, including small and medium enterprises, in addition to corporate sectors and banks, can widely benefit from gaining market opportunity by expanding and growing domestic and global business, improving value proposition and increasing market share, which can be achieved by expanding it to new customers with a lower operating cost and increased productivity (Daniel et al., 2002).

For an e-commerce strategy to be implemented swiftly, the company board staff, including chief executives and senior managers, must recognise the importance of e-commerce to accomplish better sales volumes, return on investment (ROI), stock price and market share, otherwise the plunge into e-commerce implementation without considering the successful initiatives will result in the failing of the company (Epstein, 2004). A number of studies have recently investigated the adoption of e-commerce factors in Jordan (Salhieh et al., 2011; Al-Bakri and Katsioloude, 2015). Although a few have been conducted internationally (Waidyaratne and Dassanayake, 
2006; Nickels et al., 2008), there still remain no studies in Jordan focusing on organizational culture type and its influence on e-commerce adoption.

In particular, for a developing country such as Jordan-located in Western Asia with a population of approximately 10 million- all the necessary fundamentals required for a global firm to establish a regional hub for information technology services are available. Jordan's key attribute lies in its human capital of a high quality, well trained and educated information and communication technology (ICT) workforce and its competitive cost structure (Albakri and Katsioloude, 2015). The level of e-commerce adoption differs depending on organization type, and its culture of supporting innovation and use of technology, or they could be considered a barrier to adopt business to business (B2B) e-commerce or business to consumer (B2C). This is mainly because banks are currently providing electronic services to individual customers through internet and mobile banking applications, facilitating the use of financial and non-financial transactions in addition to exclusively designed customized products to business sectors such as gateways and electronic cards.

Accordingly, one may ask- which organizational culture type allows organizations to better adopt e-commerce? In order to have successful e-commerce ventures, companies must adhere to the vision of implementing a new structure, strategy and systems. Hence the present study, which seeks to investigate the influence of different organizational cultures on e-commerce adoption in Jordanian commercial banks. Indications of market illustrate that banks have begun providing products and services electronically in addition to designing products exclusively to facilitate e-commerce. Banks have been considering e-commerce as an opportunity to expand their business and in the way they provide services and products to customers. Adoption of e-commerce will also increase banks' exposure to coping with challenges, including human capital, infrastructure and strategic vision of the whole entity.

E-commerce has grown exponentially since its early stages. According to eMarketer journal, the explosive pace at which this industry has developed can be seen in the rise in e-commerce sales from $\$ 1.2$ trillion in 2013 to more than $\$ 1.47$ trillion in 2014. The estimated number of e-commerce users in the Middle East is 90 Million. 15\% of Middle East business has an online presence. The volume in 2013 reached $\$ 9$ billion, and was expected to reach $\$ 15$ billion in 2015. The Central Bank of Jordan (CBJ, 2016) also recently published that the usage amount through eFAWATEER.com for the first 6 months alone was 7 million Jordanian Dinars for 130 thousand transactions processed through online direct debit.

\subsection{Research Problem}

This study seeks to illustrate the factors in organizational culture that significantly contribute to the adoption of e-commerce in the organization. The adoption of e-commerce in organizations can vary widely, from the simple use of e-commerce to the more innovative use of online platforms to deliver services to users including capital, influence and partners. Banks have become the new star to move transaction flow from offline to online presence, transferring customer services and delivering their needs through online channels. E-commerce adoption and online application improvement among the banking sector have improved service quality, reduced cost and expanded customer base reach. Furthermore, it has provided customers with a variety of options to conduct transactions, including automated teller machines (ATMs), mobile applications, Interactive Voice Response (IVR), websites and many more. Accordingly, e-commerce adoption in Jordanian organizations was measured in this study based on the model shown in Figure 1 below, listing the organizational cultures of clan, adhocracy, hierarchy and market (Cameron and Quinn, 2006). 
Flexibility and

discretion

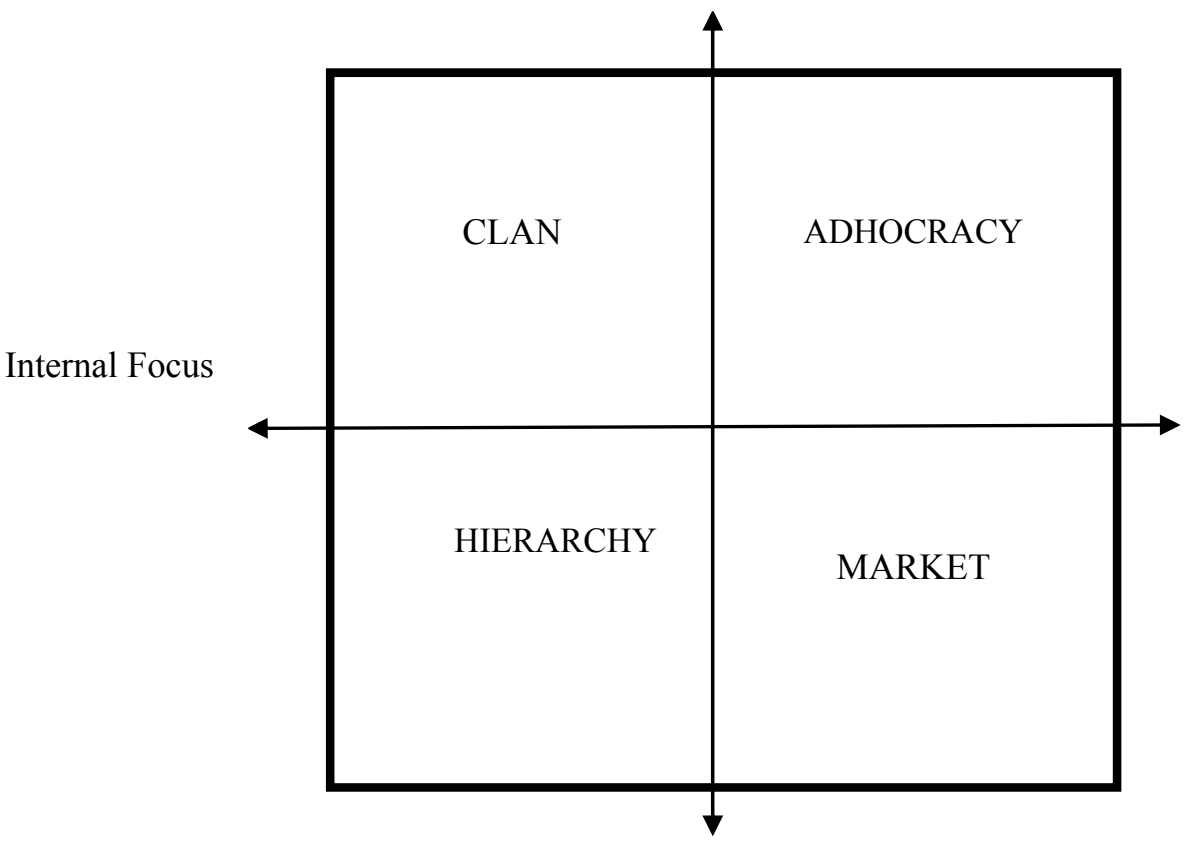

External Focus

Stability and

control

Figure 1. Organizational Culture Typology, adopted from Cameron and Quinn (2006)

\subsection{Importance of the Study}

With the revolution of the internet and communication technology and the tremendous growth of e-commerce, much of the recently conducted research focused on studying customers' requirements to fulfill their needs, perceived usefulness and customer experience. This was in order to build trust and achieve better revenues from online transactions and to adopt this new revolution of high technology (Gefen and Staub, 2000). However, few researchers have focused on investigating the preliminary point from where e-commerce begins, which is the organization and its capital, including lower and higher management, in order to better serve the end user, who is the customer, through a successful adoption of e-commerce.

This study examines the influence of different organizational cultures on e-commerce adoption in Jordanian commercial banks. Organizations differ in their deployment of e-commerce and it is necessary to examine factors that influence the implementation of e-commerce (EC) technologies as this can help the organization to appropriately design and control adoption of e-commerce. By examining the influence of e-commerce adoption in Jordan commercial banks, this study has bridged the gap to help decision makers realize the importance of organization culture and its effect on implementing e-commerce (Senarathna et al., 2014). 


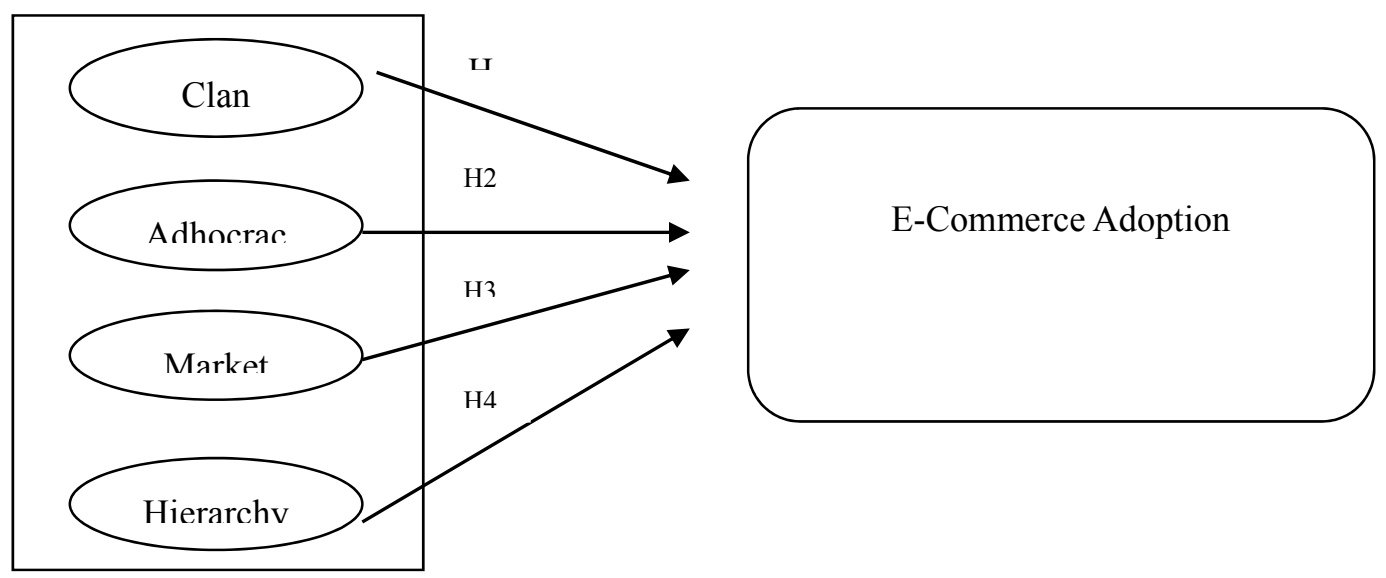

Independent Variables

Dependent Variable

Figure 2. Research's Conceptual framework

According to the researchers' knowledge, this study might be the first of its kind in Jordan to examine the influence of organizational culture on the adoption of e-commerce in Jordanian commercial banks. This study highlights the importance of the internal structure of the organization and its influence on e-commerce adoption. Cameron and Quinn's (2006) typology of organizational culture was referred to in the theoretical framework of the present study in its examination of clan, adhocracy, market and hierarchy type of organizations, and e-commerce adoption among Jordanian commercial banks.

\section{Literature Review}

Corbitt (2000) argues that for a company to transform its offline business to offer online high technology, it requires more than an initiation of a specialized department; it may be more important to revise the whole organization culture and internal structures. The literature review presented thus aims to support the objective of this study, by offering various definitions of e-commerce and reviewing a wide range of related studies. Research concerning organizational culture, including the four types- clan, adhocracy, market and hierarchy- and e-commerce adoption (Cameron and Quinn, 2006) are is also discussed in order to determine the context of the present study and place it appropriately amongst existent research.

\subsection{E-commerce: Definition and Importance}

Electronic commerce, or "e-commerce", is a relatively new concept that intruded business terminology in the 1970s. Generally, e-commerce includes "any form of economic activity conducted via electronic connections" (Wigand, 1997). E-commerce companies are divided into two types: 1. Pure.com companies- businesses that sell only through the internet and, 2. Hybrid e-commerce companies, where transactions take place online and through a physical entity (Mosesuv \& Sahawneh, 2005). Salhieh and Hijazi (2011) investigated the assessment of e-banking service readiness in Jordan, and their study found that there are three points of view to assess e-banking readiness in Jordan. These were identified as the perception of bankers, perception of customers and the IT infrastructure in banks. Researchers have recognised that e-banking adoption has reached a notable level of importance among bank managers, and that even customers have become increasingly positive about embracing new online banking channels. However, IT employees' skills remain the dominant fear.

Al-Somali et al. (2013) recently investigated an e-commerce adoption model that takes particular stages into account (interactive, non-interactive and stabilized), in addition to technology and organization factors that have influenced the implementation and adoption of e-commerce. Data was also gathered from manufacturing and services companies in Saudi Arabia (SA) to disclose motives and obstacles for e-commerce adoption. The study revealed that managers are ultimately the key to adopting e-commerce in SA. Government support and regulations are also considered critical determinants for encouraging e-commerce adoption in organisations and play key roles in defeating obstacles, challenges and associated risks. The study employed exploratory factor analysis and structural equation modeling, and identified that the regulatory environment implemented in the country is a major aspect that ought to be considered by companies considering adopting e-commerce. 
Al-Bakri and Katsioloude (2015) explored internal and external organizational factors influencing e-commerce and its systems by Small and Medium Enterprises (SME) in Jordan. The authors used a model covering the factors that supported e-commerce adoption using confirmatory factor analysis. This allowed an exploration of the relationships between factors, and facilitated both quantitative and qualitative approaches to the research. These included interviews to measure awareness and adoption in e-commerce among SMEs in Jordan. The study found that the adoption of e-commerce by SMEs has been influenced by both internal and external organizational factors, mainly readiness, strategy, manager's perceptions and external factors by partners. The study suggested that the most important factors influencing the achievement of maximum benefit were readiness and external pressure. Aghaunor and Fotoh (2006) previously conducted a study identifying the variables that influenced the adoption of e-commerce, namely: top management support, organizational competency, IT capability, perceived benefits, perceived comparability, perceived complexity, supporting industries, market and government readiness. The results of the study indicated that banks with top management support and commitment to e-commerce have a better chance of adopting e-commerce. Furthermore, banks with suitable IT and business resources and proper infrastructure are more likely to adopt e-commerce.

\subsection{Organizational Culture and the Adoption of E-commerce}

To date, there is no unique accepted definition of organizational culture. Kilman and Saxton (1985) identified culture as "the stated philosophy, ideology, values, assumption, beliefs, hope, behaviors and norms that bound the organization together". George et al. (2002) offered the definition as an "informal design of values, norms that control the way people and groups within the organization interact through each other and with parties outside the organization". A number of researchers have linked organizational culture with the adoption of e-commerce, and investigative studies have revealed that for implementation and appropriate adoption to take place effectively, the organization culture should be a function of strength to fit the innovative new climate of high technology (e.g., Klein \& Sorra, 1996).

Cameron and Quinn (2006) developed an instrument known as the Organizational Culture Assessment Instrument (OCAI). Cameron and Quinn (2006) used the OCAI as a method to specify the changes needed in the organization's culture through a process of determining its position, available resources and developing strategies for e-commerce operations that are consistent with the overall organization strategy. Cameron and Quinn (2006) argue that the implementation of cultural change requires identification and altering of organizational culture; "A change in culture depends on the implementation of behaviors by individuals in the organization that reinforce the new cultural values and are consistent with them". Valencia et al. (2011), in their study, asserted that innovation is crucial for attaining a competitive advantage for companies. Innovation, versus imitation, motivates companies to launch new products and become pioneers on markets. Many factors have been shown to be determinants for supporting an innovative organizational orientation, and one of them is organizational culture. The paper found that organizational culture is a clear determinant of innovation strategy. Moreover, adhocracy cultures foster strategies for innovation, and hierarchical cultures promote imitation cultures.

In a study in progress, Nickels et al. (2008) described the effect of organizational culture on levels of e-commerce adoption. While e-commerce has been researched in some detail, the importance of organizational culture at the level of e-commerce adoption has not been studied in depth. Organizational culture can be a limiting factor in the acceptance of technological change, and has also been linked to organizational performance. Organizational cultures with an emphasis on external orientation and flexible structures, or "adhocracies," are characterized by leaders who are innovators and risk takers. An argument can be made that a culture promoting innovation and risk acceptance would provide the support needed for higher levels of adoption of new technologies. Research (Klein \& Sorra, 1996). In IT adoption and e-commerce has shown the strategic benefits of early adoption of e-commerce, as well as a greater extent of e-commerce adoption. The current fast-developing business environment demands a change in assumptions, values and in the way of doing business. As e-commerce activities continue to grow exponentially in volume, an increase in demands on organizations would change the ways in which they interact with customers, suppliers and business partners. In order for organizations to remain competitive in e-commerce capabilities, it is crucial that they assimilate an organizational culture environment which promotes innovation, risk-taking and flexibility.

In their empirical study of SMEs in the USA, Grandon and Pearson (2004) found that the synergy between an organization's culture and the adoption of e-commerce has a strong influence on e-commerce adoption in SME organizations which don't utilize innovation and where the use of new technologies is an obstacle. The research model suggested three factors that are influential in the perception of strategic value of other information technology; operational support, managerial productivity and strategic decision aids. In this study, the 
researchers also identified four factors that influences e-commerce adoption, and stated them as organizational readiness, external pressure, perceived ease of use and perceived usefulness.

Kumarasingh and Hoshino (2003) aimed to examine the influence of the organizational factors of culture, structure and strategy on organizational performance. Their research findings indicated that the relationship among members, speed of decision making, product strategies and innovativeness, quality of employees and technology defines the difference between a successful and unsuccessful organization. Regression results illustrated that the ROI was also influenced by cultural, structural and strategic variables. Xenikova and Simosi (2006) then examined the relationship between transformational leadership and organizational culture orientation, as well as its influence on business units' performance. The study findings revealed that the achievement and adaptive cultural orientations, including leadership, had a direct effect on performance. The importance of information technology as an enabler of an organization model and innovative strategies was highlighted by Wolf (2011). The results of this research demonstrated how institutional reforms could foster the diffusion of mature technologies, and how leadership and clear vision lead to consistency between organization management and technology to facilitate the exploitation of full benefits with innovation

\subsubsection{Clan Culture and E-commerce}

A Clan culture has been defined by Cameron and Quinn (2006: 42) as "a friendly work environment where people have the ability to share about themselves. It is like being with friends and family at work. The internal climate is the main determinant of success". Berrio (2003) explained a clan culture as "an organization that focuses on internal continuance with elasticity, care for employees and customers". Lund (2003) examined an empirical study to test the impact of organizational culture on job satisfaction in a survey of marketing professionals in a cross - section of firms in the USA. The results indicated that job satisfaction was diverse across organizational cultural classification. Job satisfaction was positively related to clan culture, which positively affects the performance of the organization. Ghobakhloo et al. (2011) investigated the internal environment of the organization that affects e-commerce adoption in SMEs. The researchers used a questionnaire- based survey of managers in manufacturing SMEs in Iran. The study concluded that perceived adoption depends on employee attitude towards change and chief executives' innovativeness to adopt and support changes. A further study conducted in Taiwan (2005) examined the internal factors of organizational cultures such as technical expertise, knowledge and training available, management support and e-business system adoption. The authors gathered data through questionnaires using a factor analysis model, and the result revealed that the organizational internal factors mentioned above are closely related to e-business adoption. Knowledge sharing, however, did not have significant effect on the e - business systems adoption (Lin and Lee, 2005). In his article on the corporate culture of a clan organization, Chan (1997) suggested that companies who create social reserves are the best performers in a wild market or industrial environment when uncertainty conquers. These social reserves are seen to encourage a clan based culture. The clan culture provides guidelines and benchmarks for other companies to manage strategically in an uncertain business environment. The article further proposed that a clan culture organization is an ideal organization type whose formation, as well as social and cultural characteristics, could be rivalled. This leads us to the below hypothesis:

H1: Clan culture characteristics have no significant influence upon e-commerce adoption in Jordanian commercial banks.

\subsubsection{Adhocracy Culture and E-commerce}

Adhocracy culture is characterized as a "dynamic and creative workplace, people are risk takers, and leaders in the company are risk oriented whereby the organization is committed to facing innovation and forward looking to being unique in the outcome offered, whereby the organization focuses on external positioning with a high degree of elasticity and individual independence" (Cameron and Quinn, 2006: 50). McDermott and Stock (1999) investigated how organizational culture is associated with the implementation of advanced technology. The data was collected from manufacturing companies, and regression analysis was employed to test the relationship between managers' perception of organization culture and success of technology adoption to benefit the company. Conclusions considering the influence of an adhocracy culture type of e-commerce adoption were contradictory and indicated that e-commerce adoption was linked to risk appetite of the organization and that market culture was related to competitive benefits.

Senarathna et al. (2014) studied the influence of different organizational cultures on e-commerce adoption in SMEs. Data was collected using a portal survey questionnaire and subsequently analyzed using quantitative analysis methods. The study found a positive relationship between adhocracy and e-commerce adoption. Nickels et al. (2008) also investigated the effect of the growth of organizational culture on e-commerce adoption. The 
study suggested that organizational culture can be a barrier to the acceptance of technology and highlighted its link with the organization's performance. Data was also collected from senior managers whose functions included formulation of strategy or execution of strategies using the Organizational Culture Assessment Instrument (OCAI) by Cameron and Quinn (1999: 117). The researchers found that organizational cultures which focus on external orientation and elastic structure, or "adhocracies," are symbolized by leaders who are innovators and have a higher degree of risk acceptance. The study concluded that an organization which encourages risk acceptance and innovation enhances the potential for adoption of the latest technology. More recently, Parikh (2016) described this type of culture to be that of innovation, problem solving and flexibility. In the study, Parikh (2016) showed that for an organization to implement highly innovative and successful products, its staff must be wholly supported, in contrast to controlling strategic summit, which is traditionally more common. This leads us to the following hypothesis:

H2: Adhocracy culture characteristics have no significant influence on e-commerce adoption in Jordanian commercial banks.

\subsubsection{Market Culture and E-commerce}

Market culture has been defined Cameron and Quinn (2006: 54) as a "result oriented workplace, focusing on gaining market share and penetration, focusing on external continuance with the need for steadiness and power". Homburg and Pflesser (2000) investigated the effect of market oriented organizational culture on performance and its effect on external markets. The researchers adopted a qualitative approach to the data prior to performing a quantitative scale development targeting general managers, marketing managers and managers from other functional departments. The study showed that the market organizational culture adopted by the organization has a notable impact on innovation and development depending on dynamism in the market.

Luntraru and Esau (2012) later investigated the consequence of the market orientation type of organization culture and the performance of adopting technologies in small and medium enterprises. In their study, the researchers suggested that in order for an organization to change, it should first analyze its learning capabilities and determine the market orientation to enhance company performance. The study concluded that there is no relationship between market culture and adoption of new technology to improve performance. Nickels et al. (2008: 267) defined market culture as "the opposite of the clan culture", stating that "a major characteristic is a hard-driving, competitive organizational environment. Managers are demanding, and a major organizational goal is winning in a competitive marketplace". This leads us to the below hypothesis:

H3: Market culture characteristics have no significant influence on e-commerce adoption in Jordanian commercial banks.

\subsubsection{Hierarchy Culture and E-commerce}

Hierarchical culture has been defined by Cameron and Quinn (2006: 59) as "a formal and strict policy defined well to lead the work tasks and people, whereby the organization focuses on internal continuance with the need for constancy and control". Senarathna et al. (2014) studied the influence of different organizational cultures on e-commerce adoption. Data was accumulated using a portal survey questionnaire and analyzed using quantitatively. The study found a negative relationship between hierarchy culture characteristics and e-commerce adoption, with the authors recommending that SMEs who are willing to adopt e-commerce should consult policy makers and revise business communities related to e-commerce initiatives.

Zammuto and O'Connor (1992) analyzed the relationship between organizational culture and advanced technology implementation using a survey methodology to gather data. It was suggested that organizations typified with flexibility are more successful and open to the implementation of high technology, and exhibit greater efficiency than organizations characterized by control and hierarchical culture. Parker (2012) explored the attractions and problems of flatness as an alternative to hierarchy in a unique study, and found that hierarchical culture can significantly affect the success of the organization. This is mainly because hierarchical activities were not helpful in socialization and internalization. This culture was also not particularly beneficial in management strategy and plans. This leads to the below hypothesis:

H4: Hierarchy culture characteristics have no significant influence on e-commerce adoption in Jordanian commercial banks

Four major types of organizational culture characteristics, as cited in Cameron and Quinn (2006, p. 75), have been discussed above. The present study examines the influence of different organizational cultures on the adoption of e-commerce in Jordanian commercial banks, and draws attention to the most pertinent to be implemented in the country's commercial banks. Organizations differ in their deployment of e-commerce, and it 
becomes necessary to explore the factors that influence implementation of EC technologies as this aids the organization to appropriately design and control the adoption of e-commerce. By investigating the influence of e-commerce adoption in the banking sector, this study has essentially bridged the gap to allow decision makers to realize the importance of organization culture and its effect on implementing e-commerce.

In reference to the theoretical part investigated, it was found that e-commerce has a significant influence on our daily life, affecting our purchasing and selection behavior, offering us a personalized experience which broadens the organization brand locally and internationally. Therefore, in order for banks to emerge their role in e-commerce, they began to deliver credit, deposits products and inquiries electronically. The banking sector has recently been disrupted by a number of financial and non-financial institutions providing similar products and services at a lower price due to lower cost. Some large banks began to offer products exclusively designed for e-commerce. For Jordanian commercial banks to catch the revolution in adopting e-commerce, they should test their readiness by exploring the cultural type in the organization, especially within senior levels of management and among departments that are mainly included in the decision making process and who have influence on employees in lower levels for the adoption process to be implemented correctly. Furthermore, the Jordanian government and Central Bank of Jordan have been encouraging banks, entrepreneurs and SMEs to adopt e-commerce. The Government provides several incentives in the form of subsidies and tax-rebates. These should be granted and implemented to further encourage the adoption of e-commerce transactions, which will also lead to ultimately lowering the cost of serving the customer.

The banking sector has seen tremendous benefits of e-commerce. Primarily, e-commerce has reduced the pressure of bank employees and raised the standard of customer service. Customers of banks are also now more satisfied as they feel more at ease knowing that there is an advanced e-commerce system of banks. Many economic, marketing and technological forces have attracted the banking sector towards the e-commerce system.

\section{Study Methodology and Data Collection Method}

\subsection{Population of the Study}

The targeted population of the study is Jordanian commercial banks which are 13 in total. Since banks contributed to the development and support of modern trade, they can precede in their achievement in developing and growing the concept of electronic commerce. The banking sector is selected as it is considered the largest in the service sector, well-structured and well-distributed. Jordanian commercial banks are also in a phase of adopting e-commerce with the aim of transforming society from cash to cashless. The questionnaire was distributed to senior levels in the mentioned banks, including section heads and higher in the management in each bank due to their important role in developing a clear-cut e-commerce adoption and sending signals about the importance of e-commerce to different divisions of the organization. Jordanian commercial banks currently provide relatively common online services, or "e-banking", such as Internet Banking and Mobile Applications to customers.

The questionnaire was sent to senior representatives of the banks who work in business departments, product development e-channels and marketing. Managers and higher level officials, section heads and assistant managers were selected as the characteristics of a successful e-commerce venture company must encompass many aspects, mainly leadership and its commitment by senior managers to consider a significant role for e-commerce in the organization (Senarathna et al., 2014). The rationale for choosing this sample in the banking sector was that they are more in touch in developing products and services and have greater and more up-to-date knowledge of ICT. They are also the key developers and adopters of e-commerce and hold the ultimate influence on whether the whole organization works online or offline.

The Jordanian banking system comprises the Central Bank of Jordan (CBJ) and all licensed banks consisting of commercial, Islamic and foreign banks which operate in Jordan (Central Bank of Jordan, 2015). At the end of 2015, the number of licensed operating banks in Jordan reached 26 banks. In total, 16 are local banks, and 10 are foreign (Association of Banks in Jordan, 2014). These banks operate under the regulation of the CBJ. Table 1 below clarifies the targeted population of the study. At the time of the study, the total number of employees in Jordanian commercial banks was 15,033. 145 questionnaires was distributed to the target of stud. The target population did not include employees in branches or departments other than business development, who are considered the implementers in e-commerce and the developers of products and services to the end user- the customer. 
Table 1. Jordanian Commercial Banks and Number Employees

\begin{tabular}{ll}
\hline Banks & Number of Employees \\
\hline Arab Bank & 2934 \\
Bank of Jordan & 1489 \\
Jordan Ahli Bank & 1416 \\
Cairo Amman Bank & 1614 \\
Jordan Kuwait Bank & 1100 \\
Jordan Commercial Bank & 695 \\
The Housing Bank for trade and Finance & 2363 \\
Arab Banking Corporation (ABC) & 500 \\
Arab Jordan Investment Bank & 714 \\
Investment Bank & 461 \\
Etihad Bank & 915 \\
Societe General & 257 \\
Capital Bank of Jordan & 575 \\
\hline
\end{tabular}

This study sample was selected as it was the most appropriate for the purposes of the study. The unit of analysis of the research was composed of all employees occupying managerial positions in the Jordanian commercial banks. These comprised top to low managerial roles including section head, assistant managers, managers, executive managers and higher management officials who worked in departments related to business and product development, marketing and e-channels in the 13 Jordanian commercial banks. The study focused particularly on management in business and project development, because their positions in the respective organizations suggest that they are part of the decision making process.

The data collection procedure entailed a number of stages. The researchers began by obtaining the contact information of the Jordanian commercial banks from their official website and contacting the human resource or training and development departments, those who could distribute the survey in each bank. These departments also determined the number of questionnaires that could be distributed in each bank. A preliminary interview explaining the purpose of the study was then conducted with the appointed member of the human resource or training and development department. Following the interview, the HR representative was asked which method of delivering the questionnaire the bank preferred (online or hard-copy). The majority preferred access to the questionnaire via an online link, whilst others requested hard-copies to be delivered by hand. All headquarters of these banks were situated in Amman.

The distribution of the questionnaire began in early April 2016, and the data collection period continued until mid-May 2016, with the overall data gathering process taking approximately six weeks. To manage the data collection process, the spread sheet was used for tracking returned questionnaires. To encourage a high number of responses, the questionnaire was written in both Arabic and English versions to facilitate understanding for all potential participants. The respondents assured of total confidentiality through the inserted statement "Please be assured that all information you provide will be kept confidential and will only be used for research purposes". Furthermore, a weekly follow-up was offered by phone or email following return of the original survey.

The questionnaire was the instrument used to gather information from the target population for the research study. The questionnaire included items to measure the respondents' views on the bank's culture type (Clan, Adhocracy, Market, \& Hierarchy) based on specific questions concerning the leadership style, type of environment, innovation and risk appetite in each bank. The extent of e-commerce adoption was also measured based on the implementation of online solutions at the bank in order to transfer the bank from a provider of products and services offline to establishing an online existence. Finally, the internal process and communication between employees was analyzed (Cameron \& Quinn, 2006).

This structured questionnaire consisted of fifty- eight questions distributed across three sections. Section 1 included 8 items about the respondent: demographic items and the bank including job title, educational background, years of experience in the banking sector and general questions about the implementation of the main service in e-commerce. Section 2 contained 16 items about e-commerce activities carried out in each bank (Mobile Application, website, social media existence and advertisement, online transactions, internal 
communication, management interest and understanding in applying e-commerce and customized products and services for e-commerce expansion to business sector). Respondents were asked to evaluate the extent to which the bank develops and applies ecommerce. Section 3 contained 34 items about organizational cultural type in each bank based on dominant characteristics of the bank, organizational leadership and management of employees, organization glue, strategic emphasis and criteria of success. Respondents were asked to evaluate each section and the extent to which it reflects the type of culture in the bank (Cameron and Quinn, 2006; Senarathna et al., 2014).

The questionnaire used a Likert-type scale with five scale categories: 1- Strongly Disagree, 2- Disagree, 3Neither agree nor disagree, 4- Agree and 5- Strongly Agree. The responses were therefore measured based on a rank-order of importance and prevalence in the bank. The items included in the questionnaire represented established items previously used to measure each organizational culture and e-commerce adoption. Thus, all constructs of the theoretical framework were based on theoretical concepts from related research. The scales and items for measuring the research constructs were adapted mainly from Cameron and Quinn (2006), Senarathna et al. (2014) and Nickels et al. (2008).

\subsection{Validity and Reliability}

Validity is about accuracy and whether the instrument measures what it is projected to measure. Reliability is about steadiness and stability; it is the prospect that there will not be changes in answers each time the measures are used (Sekaran \& Bougie, 2009). These measures were employed to ensure that the tool used in the study actually measured what was intended. Then the questionnaire was piloted by sharing it with a number of specialists and academics in the field to assess the entire questionnaire. This involved confirming that it was well-designed and user-friendly to avoid confusion, that it facilitated clarity and eliminated incomprehensible questions which may lead to inappropriate response types. After the feedback was retrieved, the questionnaire was adjusted accordingly and subsequently disseminated to the sample study.

A measure is reliable when similar outcomes are yielded over time and over different circumstances. Internal consistency is the proportion which motivates the reliability concept (Zikmund, 2003). Following the previous studies, the Cronbach's alpha was used as a measure of internal consistency, or "reliability". Cronbach's alpha reliability coefficient normally ranges between 0.0 and +1.0 . The closer Cronbach's alpha is to 1 , the higher the internal consistency reliability. However, the minimum of Cronbach's alpha coefficient is 0.6 (Hair et al., 1998).

Table 2. Cronbach's alpha coefficients

\begin{tabular}{lll}
\hline Study construct & Number of Items & Cronbach's Alpha Values \\
\hline E-commerce activities & 16 & 0.724 \\
Clan Culture & 10 & 0.855 \\
Adhocracy Culture & 8 & 0.734 \\
Market culture & 9 & 0.699 \\
Hierarchy Culture & 7 & 0.891 \\
Organizational Culture & $\mathbf{3 4}$ & $\mathbf{0 . 8 4 5}$ \\
\hline
\end{tabular}

Table 2 above illustrates that all values are greater than 0.60 , indicating that all values exceeded the minimum acceptable value of 0.60 . This is evidence that the internal consistency reliability was very good, acceptable and could be considered reliable to achieve the research objectives.

\subsection{Test of Normality}

The Kolmogorov-Smirnov parametric test was employed to assess how close the study data was to the normal distribution, as shown in Table 3 below.

Table 3. Kolmogorov-Smirnov test

\begin{tabular}{lll}
\hline \multirow{2}{*}{ Variables } & \multicolumn{2}{l}{ Kolmogorov-Smirnova } \\
& Statistic & Sig. \\
\hline E-commerce activities & 0.067 & $0.200^{*}$ \\
Clan Culture & 0.056 & $0.200^{*}$ \\
\hline
\end{tabular}




\begin{tabular}{lll}
\hline Adhocracy Culture & 0.087 & 0.020 \\
Market culture & 0.092 & 0.011 \\
Hierarchy Culture & 0.146 & 0.000 \\
\hline
\end{tabular}

The results in (Table 3) reveal that the probability for e-commerce activities and clan culture are greater than 0.05 . This indicates that those two variables are normally distributed. However, the other variables are not. Therefore, to overcome this issue, the skewness test was conducted, where if the absolute value of skewness was less than 2, this specified that the study variables were close to the normal distribution (West et al., 1995). As shown in Table 4 below, all the absolute values of skewness of the study variables were less than 2.58 . The study variables were thus considered close to the normal distribution.

Table 4. Skewness and Kurtosis Test

\begin{tabular}{lllll}
\hline Study Variables & Skewness & \multicolumn{3}{l}{ Kurtosis } \\
\hline Adhocracy Culture & Statistic & Std. Error & Statistic & Std. Error \\
Market culture & -0.092 & 0.217 & -0.469 & 0.430 \\
Hierarchy Culture & -1.031 & 0.217 & 2.332 & 0.430 \\
\hline
\end{tabular}

Skewness and Kurtosis were conducted for the variables. If the absolute value of Skewness was less than 2 and the value of Kurtosis less than 7, this indicates that the study variables are close to the normal distribution (West et al., 1995). As shown in Table 4, all the absolute values of skewness of the study variables were less than 2. The study variables were therefore rendered close to the normal distribution.

\section{Data Analysis}

\subsection{The Relative Importance for the Main Variables}

A Likert Scale was employed in this study using a scale of 1 to 5 to determine the extent of agreement of the study sample with each paragraph of the study tool. These scores were then transformed to quantitative data to allow statistical measurement. In order to specify the relative importance of the questionnaire items, to highlight the degree of adoption of e-commerce activities and to determine the organization culture at the Jordanian commercial banks, an ordinal scale was developed to give meaning to the arithmetic mean. Table 5 shows the scale of the relative importance of the items calculated according to the following formula: (The Maximum limit (5)-The Minimum limit)/ number of required measurements (3). The result (1.33) was then added to each scale (Nael, 2006).

Table 5. Scale of Relative Importance of questionnaire items

\begin{tabular}{ll}
\hline Scale & Relative Importance \\
\hline $1-2.33$ & Low \\
$2.34-3.67$ & Average \\
$3.68-5$ & High \\
\hline
\end{tabular}

\subsection{Descriptive Statistics}

The descriptive statistics for the study variables are illustrated in Table 6 below:

Table 6. Descriptive statistics of the study variables

\begin{tabular}{llll}
\hline Study Variables & Mean & Std. Deviation & Relative importance \\
\hline Organizational Culture & 3.87 & 0.412 & High \\
Clan Culture & 3.45 & 0.621 & Average \\
Adhocracy Culture & 3.48 & 0.540 & Average \\
Market culture & 4.32 & 0.437 & High \\
\hline
\end{tabular}




\begin{tabular}{llll}
\hline Hierarchy Culture & 4.04 & 0.733 & High \\
E-commerce Activities & 3.38 & 0.481 & Average \\
\hline
\end{tabular}

It can be seen from Table 6 that the relative importance for e-commerce activities, Clan culture and Adhocracy culture are average. Market, Hierarchy and Organization cultures, however, are relatively high. This indicates that the participating respondents had a positive attitude towards the e-commerce activities and organization culture in Jordanian commercial banks. The above results also support that notion that Jordanian commercial banks have the necessary technical, managerial and other relevant skills to implement electronic commerce. Moreover, the data indicates that the banks have a sound understanding of electronic commerce application that allows them to provide customized electronic products for businesses and conduct transactions online.

\subsection{Inferential Statistics: Hypotheses Testing}

To examine the hypotheses and ensure there were no problems in the study model, the Collinearity Diagnostic Test was employed. Multicollinearity happens when there is a strong correlation between more than two independent variables. Perfect collinearity occurs when at least one independent/predictor variable is a perfect linear combination of the others. This means that if there are two independent variables that are perfectly correlated, the values of $\beta$ for each variable are interchangeable (Gujarati and Porter, 2010).

Table 7. Collinearity diagnostics

\begin{tabular}{lll}
\hline & Collinearity Statistics & VIF \\
\hline Variables & Tolerance & 1.316 \\
Adhocracy Culture & 0.760 & 1.321 \\
Market culture & 0.757 & 1.118 \\
Hierarchy Culture & 0.894 & 1.145 \\
\hline
\end{tabular}

It is evident from the above Table 7 that the Variance of Inflation (VIF) values are near to 1 and do not exceed (10). The Tolerance values are also greater than 0.1 , indicating that collinearity was not a problem in the study model (Gujarati \& Porter, 2010). To assess the study hypotheses, the multiple regression analysis was applied. The results of the study hypotheses are displayed below:

Table 8. Regression analysis test

\begin{tabular}{|c|c|c|c|c|c|c|c|c|c|}
\hline \multirow{3}{*}{ Variables } & \multicolumn{4}{|c|}{ Model summary } & \multicolumn{2}{|c|}{ ANOVA } & \multicolumn{2}{|c|}{ Coefficients(a) } & \multirow{3}{*}{$\begin{array}{l}\begin{array}{c}\text { Unstandardized } \\
\text { coefficients }\end{array} \\
\text { Beta }\end{array}$} \\
\hline & $\mathbf{R}$ & R Square & $\begin{array}{l}\text { Adjusted } \\
\text { Square } \\
\end{array}$ & $\mathbf{R}$ & F-value & Sig & \multirow[t]{2}{*}{$\mathbf{t}$} & \multirow[t]{2}{*}{ Sig.(P-value) } & \\
\hline & 0.395 & 0.156 & 0.128 & & 5.562 & 0.000 & & & \\
\hline Constant & & & & & & & 6.185 & 0.000 & 3.057 \\
\hline Clan Culture & & & & & & & 1.906 & 0.059 & 0.142 \\
\hline Adhocracy Culture & & & & & & & 2.458 & 0.015 & 0.211 \\
\hline Market culture & & & & & & & -1.004 & 0.317 & -0.098 \\
\hline Hierarchy Culture & & & & & & & -1.994 & 0.048 & -0.117 \\
\hline
\end{tabular}

Table 8 illustrates that the multiple correlation coefficient $\mathrm{R}=0.395$ indicates there is a strong positive correlation between organization culture and e-commerce adoption. Also, the value of $R^{2}=0.156$, meaning that the organization culture can account for $15.6 \%$ of the variation of e-commerce adoption. The adjusted $\mathrm{R}^{2}=0.128$ concerns the generalizability of the model, allowing the results to be taken from the sample and generalized for the whole population. It is noticed that the value of the adjusted $R^{2}$ is very close to the value of $R^{2}$. If the adjusted $\mathrm{R}^{2}$ is excluded from $\mathrm{R}^{2}(0.156-0.128)=0.028$. This minor decrease $(0.028)$ means that if the model has been fitted when the whole population participates in the study, the higher variance in the outcome will be 0.028 .

Also, Table 8 shows the probability of the F-value and it is significant at 0.05 , which indicates that organization culture has a significant influence on e-commerce adoption. Accordingly, the first main null-hypotheses/ hypothesis will be rejected and the alternative hypotheses accepted. Moreover, it is noticed from Table 14 that 
the P-value of Clan Culture was 0.059 and therefore higher than 0.05 . The t-calculated for this variable (1.906) was lower than the T-tabulated (1.96). This indicates that the Clan Culture has no statistical influence on e-commerce adoption. Therefore, the first null sub-hypotheses/hypothesis will be accepted.

The results in Table 8, however, show that the P-value of Adhocracy Culture was 0.015, which is lower than 0.05. Also, the t-calculated for this variable (2.458) was higher than the T-tabulated 1.96. This indicates that the adhocracy culture has a statistical influence on e-commerce adoption. Additionally, the positive value of beta 0.211 provides evidence that this influence is positive. Therefore, the second null sub-hypotheses will be rejected. However, the results in Table 8 reveal that the P-value for Market Culture was 0.317, and is therefore higher than 0.05. The t-calculated for Market Culture was -1.004 and was higher than the t-tabulated -1.96 . This indicates that Market Culture has no statistical influence on e-commerce adoption, and thus the third null-hypotheses will be accepted. It can be seen in Table 8 that the P-value of hierarchy culture was 0.048 and was thus lower than 0.05 . The t-calculated for Hierarchy Culture was -1.994 , which was lower than -1.96 . Furthermore, the negative value of beta $(-0.117)$ proves that this influence was negative, ultimately illustrating that Hierarchy Culture has a negative statistical influence on e-commerce adoption. As a consequence, the fourth null-hypotheses will be rejected and the alternative accepted.

\section{Conclusions}

The primary purpose of this study was to investigate the influence of organizational culture on e-commerce adoption among Jordanian commercial banks. The current world economy is being disrupted by new ideas and innovative technologies, and Jordan seeks to be a leader in the field rather than a follower, and the disruptor rather than the disrupted, as merging their banking services with new technology will undoubtedly aid the economy. This study will help Jordanian Commercial Banks to assess e-commerce activities and begin providing more services through online banking and offering greater online communication with customers and investors. This, in turn, will help banks to increase the customized electronic products for businesses, such as plastic money, payment gateways and online business solutions. Additionally, this will raise the potential for conducting transactions online and through efficient mobile applications (such as transfers and bill payments). The study analysis of variance reveals that adhocracy cultural characteristics are adopters in implementing e-commerce activities compared to the other cultures in the analyzed Jordanian Commercial Banks. In contrast, hierarchy cultured Jordanian Commercial Banks are not adopters of e-commerce activities. Market and Clan cultured Jordanian Commercial Banks, however, exhibit neither concern nor obvious interest for e-commerce adoption. These results echo those of Senarathna et al. (2014).

The data overall reveals that when Jordanian Commercial Banks pay attention to creative and innovative ideas, thoughts and suggestions, new products are invented. Acquiring contemporary resources to explore new opportunities will also contribute to increasing the chances of adopting e-commerce activities. Moreover, the coordination and smooth running efficiency governing the procedures and internal controls have the effect of reinforcing permanence and stability in the work environment, ultimately leading to greater e-commerce application. These results support those of Grandon and Pearson (2004).

The results also confirmed that competitive marketplace leadership is a key to success in Jordanian Commercial Banks, and that leadership style in particular exemplifies coordination and efficiency. The analyzed data revealed that formal techniques and procedures are the most important factors that govern what people do as well as the internal work in Jordanian Commercial Banks. It was also found that the nature of the bank process and work is characterized by permanence, stability and controlled structure. These features are linked to and supported by the management and leadership style that yields coordination and efficiency.

Bank management appeared to seek to create opportunities for workers who had the ability to innovate a new product that would attract the largest number of customers. This confirms that bank employees in senior levels are characterized by individuality, contributing to the diverse and dynamic bank environment. For a bank to test its e-commerce activities, it should be adopting products and services to customers and employees. Financial transactions are now being performed using banks' online banking system, Mobile applications or e-commerce system. These transactional services include presentation and payment of bills, fund transfer from one account to another, investment facilities and application for loans can be submitted on the e-commerce system of the bank. Customers can generate the periodic financial statements of their bank account by availing the internet banking facility of the bank. Long queues at the cash counter can be avoided by using the fund transfer facility on the e-commerce system of banks. The ATM service is also a form of e-commerce system to transact cash without standing in long queues at the cash counter. Other non-transactional services such as reviewing bank statements and checking balances are also being performed on the e-commerce system of banks. E-commerce should 
include employees at the bank and encompass emails, human resource portals and online internal communication between departments.

The result of how the study hypotheses reflected on the research's theoretical framework is illustrated in the diagram below (Figure 3).

Independent Variables

Dependent Variable

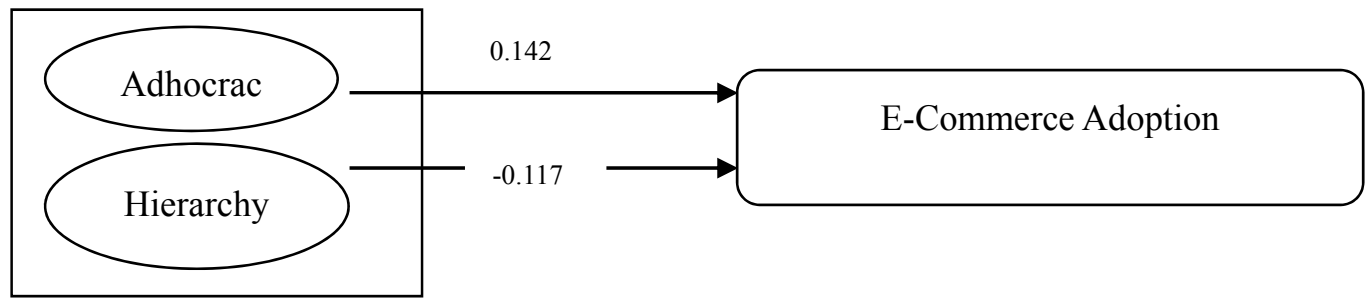

Figure 3. The Study's Modified Model

\section{Recommendations}

The following recommendations are proposed based on the findings of the study:

1) Managers need to pay greater attention to their organization culture if they pursue innovation/imitation of strategies. Depending on this orientation (to be the first company to introduce in new markets or develop new products for a market versus to follow a pioneer), companies should promote different values and norms in their organizations.

2) The study results would be beneficial for banks that are in the process of adopting new e-commerce initiatives and upgrading their existing services. Therefore, decision makers in banks should be aware of the influence of various kinds of organization culture on e-commerce adoption. As a consequence, greater effort should be directed in the promotion and alteration of preferred organization culture gearing towards a successful e-commerce edge. This is due to the importance of e-commerce implementation that leads to gaining market opportunity, increased sales to the whole and attracting new customers.

3) Encouraging banks to adopt e-commerce and recognizing the appropriate organization culture that would have a direct influence on e-commerce- technical and innovative- implementation which can enhance the customer experience and work process, increase profitability, reduce cost and achieve competitive advantage accordingly.

4) In order for an organization to implement and adapt e-commerce, it should evaluate its status quo in terms of characteristics and the prevailing culture type to apply the adoption effectively and efficiently.

5) Marketers should have a basic role in assessing and selecting the right partner to support the organization in the implementation and adoption process. Banks should also increase training opportunities in e-commerce to raise awareness of its importance and help employees to adapt to the new concept and apply it to proper designed products.

6) For pertinent future studies, this research could be conducted using foreign banks and Islamic banks in Jordan as they have different policies and structures. The scope of the study could also be widened to explore countries other than Jordan. Finally, sectors other than banking- such SMEs- could be investigated to ascertain the influence of culture on the adoption of e-commerce.

\section{Research Limitations}

Potential limitations of the study could firstly be in the positions of the survey participants. These posed minor constraints to the study because the targeted participants were employees in managerial posts, including senior managers, divisional managers, heads of business departments and supervisors in Jordanian Commercial Banks. There was therefore some difficulty gaining access to them, especially those in the higher managerial positions. Second, whilst the survey used closed-ended questions to measure the influence of organizational culture on e-commerce adoption, making the questions easier and quicker for respondents to complete and simpler for data analysis, this nonetheless limited the responses because participants could not make inquiries or explain answers in more depth. 
Third, although participation in this research was completely voluntary, there was a chance that participants might not have responded in a completely open and honest way. This may have perhaps been due to them wanting to offer only a positive image of their bank as they were concerned about improvements, being pioneers in adoption of Omni-channels along with providing products and services online to cope with e-commerce revolution in the world.

\section{References}

Aghaunor, L. A. V. I. N., \& Fotoh, X. (2006). Factors affecting e-commerce adoption in Nigerian banks. Journal of Internet Banking and Commerce, 20(1), 23-28.

Al-Bakri, A. A., \& Katsioloudes, M. I. (2015). The factors affecting e-commerce adoption by Jordanian BANKs. Management Research Review, 38(7), 726-749. https://doi.org/10.1108/MRR-12-2013-0291

Al-Somali, S. A., Gholami, R., \& Clegg, B. (2013). An investigation into the adoption of electronic commerce among Saudi Arabian Banks. E-Commerce for Organizational Development and Competitive Advantage, 126. https://doi.org/10.4018/978-1-4666-3622-4.ch007

Association of Banks in Jordan. (2014). Annual Report. Amman, Jordan.

Awad, E. M. (2000, April). The structure of e-commerce in the banking industry: An empirical investigation. In Proceedings of the 2000 ACM SIGCPR conference on Computer Personnel Research, 144-150. https://doi.org/10.1145/333334.333375

Berrio, A. A. (2003). An organizational culture assessment using the competing values framework: A profile of Ohio State University Extension. Age, 2(699), 1-052.

Biederman, D. (2012). E-commerce comes to Asia. Traffic World, 26(9), 23

Cameron, K. S., \& Quinn, R. E. (2005). Diagnosing and changing organizational culture: Based on the competing values framework. John Wiley \& Sons.

Cameron, K. S., \& Quinn, R. E. (1999). Diagnosing and changing organizational culture: Based on the Competing Values Framework. Reading, Massachusetts: Addison Wesley.

Central Bank of Jordan. (2015). Jordan Banking System. Amman. Retrieved February, 2016, from http://www.cbj.gov.jo/uploads/banksys.pdf

Chan, A. (1997). Corporate culture of a clan organization. Management Decision, 35(2), 94-99. https://doi.org/10.1108/00251749710160232

Corbitt, B. J. (2000). Developing intraorganizational electronic commerce strategy: An ethnographic study. Journal of Information Technology, 15(2), 119-130. https://doi.org/10.1080/026839600344311

Daniel, E., Wilson, H., \& Myers, A. (2002). Adoption of E-Commerce by Banks in the UK towards a stage model. International Small Business Journal, 20(3), 253-270. https://doi.org/10.1177/0266242602203002

Epstein, M. J. (2004). Implementing e-commerce strategies: A guide to corporate success after the dot. com bust. Greenwood Publishing Group, 2004.

Gefen, D., \& Straub, D. W. (2000). The relative importance of perceived ease of use in IS adoption: A study of e-commerce adoption. Journal of the association for Information Systems, 1(1), 8.

George, J. M., Jones, G. R., \& Sharbrough, W. C. (1996). Understanding and managing organizational behavior. Reading, MA: Addison-Wesley.

Ghobakhloo, M., Arias-Aranda, D., \& Benitez-Amado, J. (2011). Adoption of e-commerce applications in Banks. Industrial Management and Data Systems, 111(8), 1238-1269. https://doi.org/10.1108/02635571111170785

Grandon, E. E., \& Pearson, J. M. (2004). Electronic commerce adoption: an empirical study of small and medium US businesses. Information and management, 42(1), 197-216. https://doi.org/10.1016/j.im.2003.12.010

Gujarati, D. N., \& Porter, D. C. (2010). Basic Economertics (5th ed.). McGraw- Hill, International Edition, USA.

Hair, J. F., Anderson, R. E., Tatham, R. L., \& Black, W. C. (1998). Multivariate Data Analysis (5th ed.). New Jersey: Prentice Hall.

Hanson, M. J., Moir, L. F., \& Grant T. S. (ed.) (2011). IT and Organization: A Delicate Partnership, in Jason Organization Development in Healthcare: Conversations on Research and Strategies. Advances in Health Care Management, 10, 271-286. https://doi.org/10.1108/S1474-8231(2011)0000010022 
Hassan, S. M., Sistani, A. J., \& Raju, R. S. (n.d.). Top Online Shopping E-companies and their Strength and Weakness (SWOT). Research Journal of Recent Sciences.

Henry. (2007). Electronic Commerce: Fundamentals and Applications.

Homburg, C., \& Pflesser, C. (2000). A multiple-layer model of market-oriented organizational culture: Measurement issues and performance outcomes. Journal of Marketing Research, 3(4), 449-462. https://doi.org/10.1509/jmkr.37.4.449.18786

Kilman, S. S. et al. (1985). Gaining Control of the Corporate Culture. Jossey-Bass.

Klein, K. J., \& Sorra, J. S. (1996). The challenge of innovation implementation. Academy of Management Review, 21(4), 1055-1080.

Kumarasinghe, S., \& Hoshino, Y. (2003). Influence of corporate culture, structure and strategy on organizational performance: an empirical study of business organizations in Sri Lanka. 経営行動科学, 16(3), 227-242. https://doi.org/10.5651/jaas.16.227

Lin, H, \& Lee, G, (2005) Impact of organizational learning and knowledge management factors on e - business adoption. Management Decision, 43(2), 171-188. https://doi.org/10.1108/00251740510581902

Lund, D. B. (2003). Organizational culture and job satisfaction. Journal of Business and Industrial Marketing, 18(3), 219-236. https://doi.org/10.1108/0885862031047313

Luntraru, A. M., \& Baesu, V. (2012). The consequences of market orientation on the organizational learning in small and medium enterprises in the Western part of Romania. Marketing from Information to Decision, (5), 525-536.

McDermott, C. M., \& Stock, G. N. (1999). Organizational culture and advanced manufacturing technology implementation. Journal of Operations Management, 17(5), 521-533. https://doi.org/10.1016/S0272-6963(99)00008-X

Mintzberg, H., \& McHugh, A. (1985). Strategy formation in an adhocracy. Administrative Science Quarterly, 160-197. https://doi.org/10.2307/2393104

Mosesov, A., \& Sahawneh, N. M. F. (2005). UAE: financial development and economic growth. Skyline Business Journal, 1, 1-11.

Nickels, D. W., Kwun, O., \& Omar, A. (2008). The effect of organizational culture on e-commerce adoption. SWDSI Proceedings, 276-283.

Parikh, M. (2016). Move over Mintzberg, let adhocracy give way to ambidexterity. Management Decision, 54(5). https://doi.org/10.1108/MD-07-2014-0483

Parker, M. (2012). Super flat: Hierarchy, culture and dimensions of organizing. Reinventing Hierarchy and Bureaucracy-from the Bureau to Network Organizations. Research in the Sociology of Organizations, 35, 229-247. https://doi.org/10.1108/S0733-558X(2012)0000035011

Salhieh, L., Abu-Doleh, J., \& Hijazi, N. (2011). The assessment of e-banking readiness in Jordan. International Journal of Islamic and Middle Eastern Finance and Management, 4(4), 325-342. https://doi.org/10.1108/17538391111186564

Sekaran, U., \& Bougie. M. (2009). Research Methods for Business: A Skill Building Approach. UK: John Wiley and Sons.

Senarathna, I., Warren, M., Yeoh, W., \& Salzman, S. (2014). The influence of organisation culture on E-commerce adoption. Industrial Management and Data Systems, 114(7), 1007-1021. https://doi.org/10.1108/IMDS-03-2014-0076

Valencia, J. C. N., Valle, R. S., \& Jimenez, D. J. (2010). Organizational Culture as Determinant of Proct Innovation. European Journal of Innovation Management, 13(4), 446-480

Villars, P., Calvert, L. D., \& Pearson, W. B. (1985). Pearson's Handbook of Crystallographic Data for Intermetallic Phases. American Society for Metals, 3258.

West, S. G., Finch, J. F., \& Curran, P. J. (1995). Structural equation models with no normal variables: problems and remedies. In Hoyle R. H. (Ed.), Structural equation modeling: Concepts, issues and applications (pp. 56-75). Newbery Park, CA: Sage. 
Wigand, R. T. (1997). Electronic commerce: Definition, theory, and context.Wolf, Heather. https://doi.org/10.1080/019722497129241

Xenikou, A., \& Simosi, M. (2006). Organizational culture and transformational leadership as predictors of business unit performance. Journal of managerial psychology, 21(6), 566-579. https://doi.org/10.1108/02683940610684409

Zammuto, R. F., \& O'Connor, E. J. (1992). Gaining advanced manufacturing technologies' benefits: The roles of organization design and culture'. Academy of Management Review, 17(4), 701-708.

Zikmund, W. G. (2003). Business Research Methods (7th ed.). Thompson South-Western: Ohio.

\section{Copyrights}

Copyright for this article is retained by the author(s), with first publication rights granted to the journal.

This is an open-access article distributed under the terms and conditions of the Creative Commons Attribution license (http://creativecommons.org/licenses/by/4.0/). 